\title{
Differential Expression of Two Expansin Genes in Developing Fruit of Cracking-susceptible and -resistant Litchi Cultivars
}

\author{
Wang Yong \\ South China Botanical Garden, The Chinese Academy of Sciences, Guangzhou ReYiJu 510650, The \\ People's Republic of China; Graduate School of the Chinese Academy of Sciences, Beijing 100039, \\ The People's Republic of China \\ Lu Wangjin and Li Jianguo \\ College of Horticultural Science, South China Agricultural University, Guangzhou 510642, The People's \\ Republic of China \\ Jiang Yueming 1 \\ South China Botanical Garden, The Chinese Academy of Sciences, Guangzhou ReYiJu 510650, The \\ People's Republic of China
}

\begin{abstract}
ADDITIONAL INDEX wORDS. growth, Litchi chinensis, maturation
Abstract. To understand the relationship between fruit cracking and gene expression patterns, we identified two expansin genes from litchi (Litchi chinensis Sonn.) fruit and then examined their expression profiles in pericarp and aril at different stages of fruit development, using the cracking-resistant cultivar Huaizhi and the cracking-susceptible cultivar Nuomici. Two full-length cDNAs of 1087 and 1010 base pairs encoding expansin, named LcExp1 and LcExp2, were isolated from expanding fruit using RT-PCR and RACE-PCR (rapid amplification of cDNA ends) methods. $L c E x p 1 \mathrm{mRNA}$ could be detected from the early stage of fruit rapid growth (59 days after anthesis). The $L c E x p 1 \mathrm{mRNA}$ increased and reached to the highest level at the end of growth phase ( 80 days after anthesis) in pericarp of 'Huaizhi', while the mRNA could be detected at the stage of rapid fruit growth, then increased slightly and finally kept remained almost constant in the pericarp of 'Nuomici'. Similar accumulation of LcExp2 mRNA was observed in fruit aril of 'Nuomici' and 'Huaizhi', whereas LcExp2 accumulated only in pericarp of 'Huaizhi' but did not appear in pericarp of 'Nuomici'. The results indicate that expression of two expansin genes in litchi pericarp are closely associated with fruit growth and cracking.
\end{abstract}

Litchi is a subtropical to tropical fruit of high commercial value in international trade. However, fruit cracking during growth and development is a serious problem and causes a high loss of yield and commercial value (Huang et al., 2003). In particular, 'Nuomici' and 'Guiwei', which are highly appreciated cultivars, have more serious cracking than other cultivars during fruit development (Li et al., 2001, 2003a; Peng et al., 2004). Considerable research attention has been directed at the mechanism of litchi fruit cracking involved in that the expansion of the pericarp falls behind the growth of the aril (Abuhasan and Chattopadhyay, 1996; Huang and Xu, 1983; Huang et al., 1999; Li et al., 2003a; Lin, 2001; Sharma and Ray, 1987). However, the mechanisms are still not fully understood.

Expansins are cell wall proteins that facilitate extension of cell walls in a pH-dependent manner and, therefore, are considered to be primary regulators of plant cell enlargement (Cosgrove, 1999a, 1999b, 2000a; Darley et al., 2001; McQueen-Mason and Cosgrove, 1994; McQueen-Mason et al., 1992; Whitney et al., 2000). Current research indicates that expansins bind to the surface of cellulose microfibrils, disrupt the hydrogen bonds formed with

Received for publication 8 July 2005. Accepted for publication 12 Sept. 2005. We thank Guangdong Key Laboratory of Postharvest Science, Guangzhou, P. R. China, for technical support. The financial support provided by National Natural Science Foundation of China (No. 30425040) is greatly appreciated. The first two authors contributed equally to this work.

1Corresponding author: Phone: + 8620 37252525; Fax: + 8620 37252831; Email: ymjiang@scib.ac.cn. xyloglucan molecules and allow the cell wall to extend (Cosgrove, 2000b; Darley et al., 2001; Trivedi and Nath, 2004).

In view of the capability of inducing cell wall extension and stress relaxation of expansins, we hypothesize that expansins might be related to fruit cracking during growth and development of the litchi fruit. The objective of the present study was to clone expansin genes and investigate the relationship between expansin mRNA accumulation and fruit cracking of the litchi fruit, using cracking-resistant and cracking-susceptible cultivars.

\section{Materials and methods}

Plant materials. Three 10-year-old 'Nuomici' (crackingsusceptible cultivar) and 'Huaizhi' (cracking-resistant cultivar) litchi trees were chosen for this experiment from a commercial orchard near Guangzhou, Guangdong, Peoples Republic of China, in 2004. Twenty panicles located in different directions of each tree of these two cultivars were tagged, while 10 fruit of each tree were used to measure fruit diameter on 1- or 2-week basis for a period of 7 weeks, beginning at $31 \mathrm{~d}$ after anthesis (DAA) (30 Apr. 2004) and ending at 80 DAA (18 June 2004) when $\approx 50 \%$ of fruit skin turned red. Fresh weights of individual fruit, pericarp, seed and aril were also measured. The pericarp, aril, and seed were collected, respectively, then frozen in liquid nitrogen and finally stored at $-80{ }^{\circ} \mathrm{C}$ for RNA extraction. In addition, 1 -year-old roots shoots and leaves of 'Nuomici' were sampled, frozen in liquid nitrogen, and stored at $-80^{\circ} \mathrm{C}$, for a comparative analysis of the characteristic of expansin expression in different tissues. 
RNA EXtraction. Frozen tissue (10 g) was ground to a fine powder in a mortar using a pestle in the presence of liquid nitrogen. Total RNA was extracted using the hot borate method of Wan and Wilkins (1994).

Cloning and Sequencing of expansin genes. Total RNA extracted from 'Nuomici' pulp was used as templates for the RT-PCR. The product (first-strand cDNA) was subjected to PCR amplification. Degenerate primers were designed with reference to the conserved amino acids sequences of expansins, i.e., sense: $5^{\prime}-\mathrm{G}(\mathrm{GC})(\mathrm{N}) \mathrm{CA}(\mathrm{TC}) \mathrm{GC}(\mathrm{N}) \mathrm{AC}(\mathrm{N}) \mathrm{TT}(\mathrm{CT}) \mathrm{TA}(\mathrm{CT}) \mathrm{GG}(\mathrm{N}) \mathrm{G}-3^{\prime}$, antisense: 5'-(TC)TGCCA(AG)TT(TC)TG(N)CCCCA(AG)TT$3^{\prime}(\mathrm{N}=\mathrm{A}, \mathrm{C}, \mathrm{G}, \mathrm{T})$. Reactions for the RT-PCR were subjected to one cycle of $94{ }^{\circ} \mathrm{C}$ for $3 \mathrm{~min}, 35$ cycles $\left(94{ }^{\circ} \mathrm{C}\right.$ for $1 \mathrm{~min}, 50$ ${ }^{\circ} \mathrm{C}$ for $2 \mathrm{~min}$, and $72{ }^{\circ} \mathrm{C}$ for $2 \mathrm{~min}$ ) and one cycle of $72{ }^{\circ} \mathrm{C}$ for $10 \mathrm{~min}$. PCR products of the predicted size ( $\approx 530 \mathrm{bp}$ in length) were purified and cloned into pMD-18T vector (Takara, Shiga, Japan). The nucleotide sequences of cDNAs were established for both strands using the ThermoSequenase dye terminator cycle sequencing kit and a 377 DNA sequencer (Applied Biosystems, Foster, Calif.).

AMPLIFICATION OF THE 5'-AND 3'-END REgION CDNA OF LcExp1 AND $L c \operatorname{Exp} 2$ BY 5'- AND 3'-RACE-PCR. 5'- and 3'-RACE-PCR were performed using cDNA amplification kits (Takara) according to the manufacturer's protocol. To amplify $5^{\prime}$-end fragments, sense-, antisense- and $5^{\prime}-(\mathrm{P})$-primers were designed based on the sequence of cDNA fragments of LcExpl and LcExp2, respectively. To amplify $3^{\prime}$-end fragments, the specific primers for LcExp 1: 5'-GATGTGCATTCTGTGTCAAT-3'; and LcExp2: 5'-GATATAGTGAAGGTGAGCGTG-3' were designed on the nucleotide sequences of the cDNA fragments already cloned by RT-PCR. The 5'- and 3'- RT-PCR products were cloned and sequenced as described above.

NorThern BLOT ANALYSIS. Total RNA $(10 \mu \mathrm{g})$ was separated on a $1.2 \%$ agarose-formadehyde gel and capillary blotted onto PVDF membrane (BIODYNE B, $0.45 \mu \mathrm{m}$; PALL, Tokyo). The membrane was blot-dried and cross-linked with $280 \mathrm{~nm} \mathrm{UV}$. The DIG-labeled specific probes of $3^{\prime}$-untranslated regions of LcExpl and LcExp2 were prepared with PCR DIG probe synthesis Kit (Roche, Mannheim, Germany) and primers for LcExpl (sense: 5'-TCAATGGTCACTCCTACTTCAACTT-3' and antisense: 5'-CAAACAATCAACGCTACCACACATT-3') and for $L c \operatorname{Exp} 2$ (sense: 5'-GATATAGTGAAGGTGAGCGTG-3' and antisense: 5'-AATAAAATTGAAGGCGGGAAACATG$\left.3^{\prime}\right)$. The membrane was hybridized with DIG- labeled probe for $16 \mathrm{~h}$ at $45{ }^{\circ} \mathrm{C}$ in high-SDS buffer $(7 \% \mathrm{SDS}, 5 \times \mathrm{SSC}, 50$ $\mathrm{mmol} \cdot \mathrm{L}^{-1}$ sodium-phosphate, $\mathrm{pH} 7.0,2 \%$ blocking reagent and $0.1 \%$ N-lauroylsarcosine) containing $50 \%$ deionized formamide (v/v) (Roche). Blots were washed twice at $37{ }^{\circ} \mathrm{C}$ in $2 \times \mathrm{SSC}$ and $0.1 \% \mathrm{SDS}$ for $10 \mathrm{~min}$, followed by washing twice at $62{ }^{\circ} \mathrm{C}$ in $0.1 \times \mathrm{SSC}$ and $0.1 \% \mathrm{SDS}$ for $30 \mathrm{~min}$. All blots were exposed to $\mathrm{X}$-ray for $30 \mathrm{~min}$ at $37^{\circ} \mathrm{C}$. The membranes were then subjected to immunological detection using CDP-Star, according to the manufacturer's instructions (Roche).

\section{Results and discussion}

CHANGES OF WEIGHT OF DIFFERENT TISSUES IN DEVELOPING LITCHI FRUIT. There are the same growth patterns in the whole fruit of 'Nuomici' and 'Huaizhi' litchi. Fruit growth could be divided into two stages. Stage I (0-52 DAA) was slow growth phase, which was mainly characterized by pericarp and seed growth, while stage II (52-80 DAA) was rapid growth phase, which was markedly characterized by aril growth (Fig. 1). Litchi fruit cracking of cv. Nuomici was closely associated with the rapid growth phase of the aril from 60 DAA until harvest. In this study, fruit cracking occurred in a period of 66-80 DAA. There were $26.8 \%$ and $3.2 \%$ of fruit cracking rates of 'Nuomici' and 'Huaizhi,' respectively, at 80 DAA. Huang et al. (1999) and Li et al. (2003a) reported that 'Nuomici' was a cracking-susceptible cultivar while 'Huaizhi' was a cracking-resistant cultivar in litchi producing area. In the easy-to-crack cultivar Nuomici, the weight of the whole fruit and the aril increased abruptly at 66 DAA. Although there are the similar changes in the peel weights and aril weights for these two cultivars, a much larger ratio of pericarp to aril of 'Huaizhi' than that of 'Nuomici' was observed during this growth period of 66-80 DAA. Thus, the fruit cracking of 'Nuomici' could be partially attributed to an abrupt and rapid growth of the aril in association with slow peel growth.

ISOLATION AND SEQUENCE ANALYSIS OF EXPANSIN CDNAS FROM LITCHI FRUIT. Several gene expression studies on expansins have shown that expansins are principally related to fruit growth (Brummell et al., 1999; Harrison et al., 2001; Hayama et al, 2000; Hiwasa et al., 2003). In the present study, two cDNA $\approx 530$ bp in length, named $L c E x p 1$ and $L c E x p 2$, were cloned from total RNA of ripe pulp by RT-PCR. BLAST search of GenBank revealed that LcExp 1 shared $92.7 \%$ identity with FaExp 2 while LcExp2 shared $82 \%$ identity with FaExp 6 from strawberry. Thus, the two cDNAs were considered to be cDNA of expansins. By a combination of RT-PCR, 5'- and 3'-RACE, full-length cDNA of Lc-Expl and $L c$-Exp2 was cloned. The Lc-Expl full-length cDNA was 1087-bp long and contained a 51-bp 5'-untranslated region, an open reading frame of 759, and a 227-bp 3'-untranslated region, whereas the LcExp2 full-length cDNA was 1010-bp long and contained a 75-bp 5'-untranslated region, an open reading frame of 768, and $3^{\prime}$-untranslated region of $167 \mathrm{bp}$ (Fig. 2). These two different full length cDNAs shared $58.8 \%$ identity in nucleotide sequence and $74.4 \%$ identity in amino acids. The alignment of LcExpl and LcExp2 with other fruit expansins suggested that the two deduced polypeptides were highly conserved and contained 8 cystein $(\mathrm{C})$ residues, 4 trytophan $(\mathrm{W})$ residues and a His-PheAsp (HFD) domain (Fig. 2), which were characteristics of most of the $\alpha$-expansins (Cosgrove, 1999b). The results corroborated those of Li et al. (2002, 2003b) who suggested that the expansin gene family could be as large and complex.

EXPRESSION PROFILES OF LcExp1 AND LcExp2 IN PERICARP AND PUlP OF DEVEloping 'NuOMICI' AND 'HuAIZHI' FRUIT. To examine the relationship between expansin expression and fruit cracking, RNA was extracted from pericarp and aril of litchi fruit of cracking-resistant and cracking-susceptible cultivars, and its mRNA accumulation was determined individually by Northern analysis. As shown in Figs. 3 and 4, the LcExpl and LcExp 2 had different expression in pericarp and aril of 'Nuomici' and 'Huaizhi' fruit. $L c E x p 1$ expressed intensely in pericarp but scarcely in aril; conversely, LcExp2 scarcely expressed in pericarp but intensely in aril, with no difference between the two cultivars. The mRNA could be detected at the beginning of aril growth (59 DAA) and reached to the highest levels at 73 DAA and then declined gradually at the late stage of fruit development. Furthermore, there were different expression patterns of the same expansin gene in pericarp and aril of two cultivars. The mRNA of LcExpl was detected at the beginning of fruit rapid growth at 52 DAA in 'Nuomici' pericarp, and it increased slowly but remained almost constant when the 'Nuomici' fruit expand radically (66 DAA). In contrast, the mRNA of LcExpl accumulated at the beginning of 


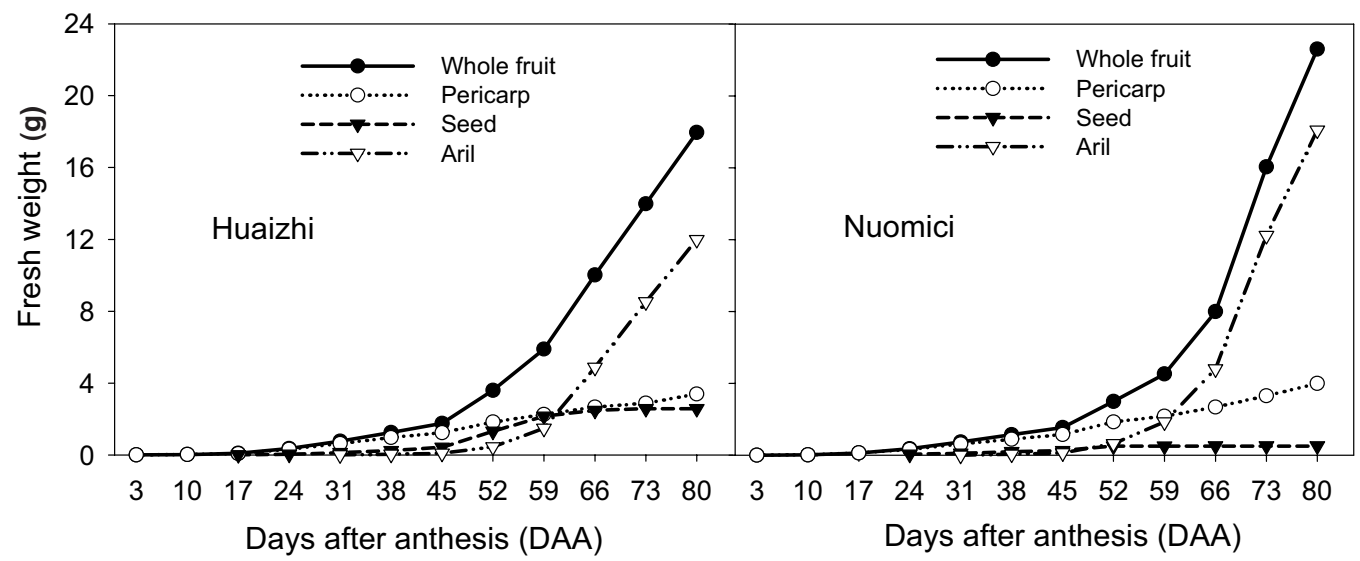

Fig. 1. Changes in weight of different tissues in 'Huaizhi' and 'Nuomici' litchi fruit.

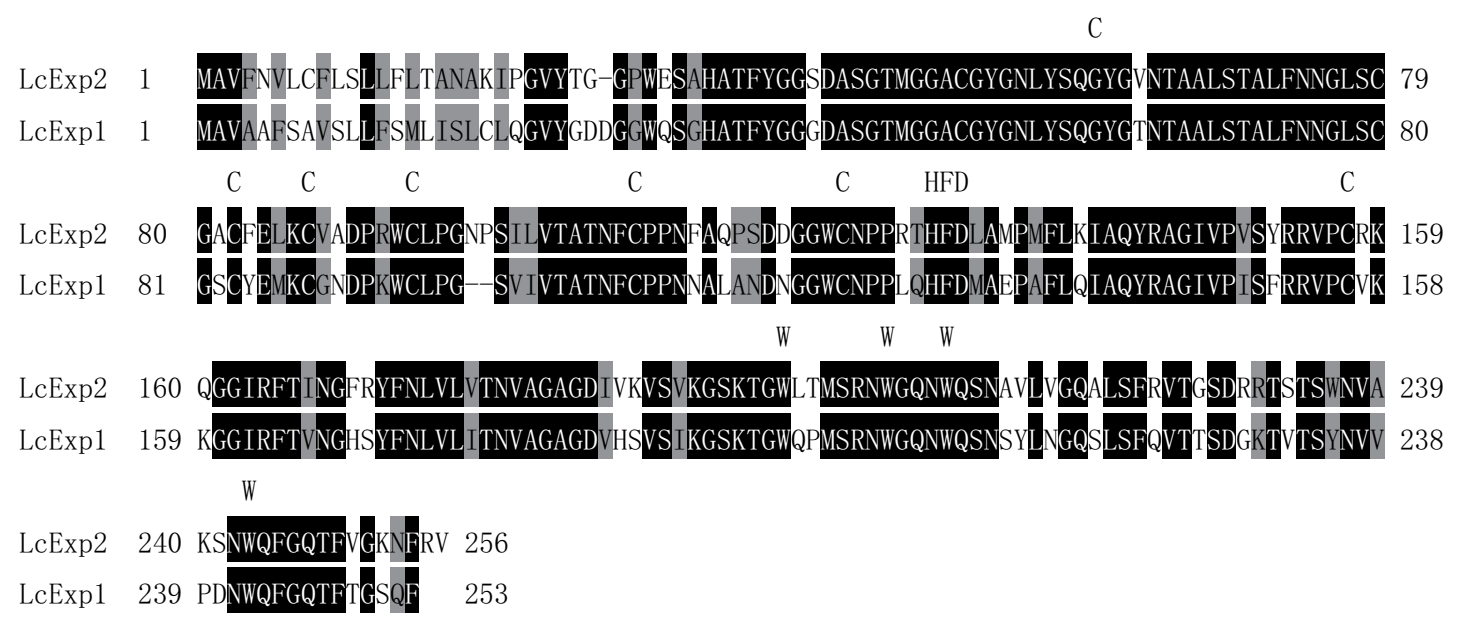

Fig. 2. Alignment of the predicted protein sequences of two cDNAs isolated from 'Nuomici' litchi pulp using RT-PCR and RACE-PCR. Proteins were aligned using the Clustal method of DNAssist 2.0. The 8 conserved cystein (C) residues, 4 trytophan (W) residues at carboxy-terminals and a His-Phe-Asp (HFD) domain defining expansin sequences are indicated above the alignment.

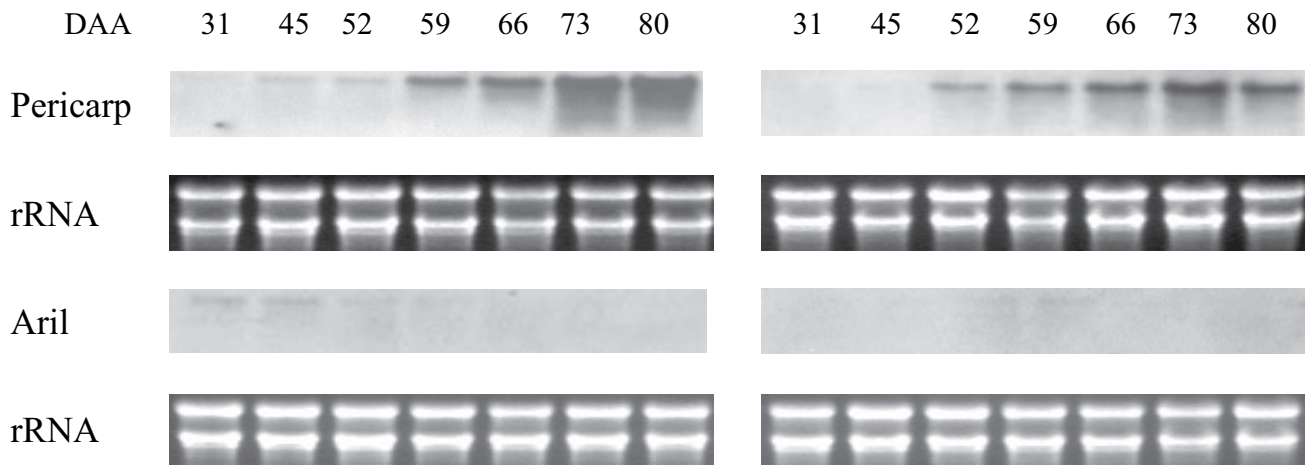

Fig. 3. Changes in mRNA accumulation of $L c E x p 1$ in the pericarp and aril of 'Nuomici' and 'Huaizhi' developing litchi fruit. Total RNA (10 $\mu \mathrm{g}$ per lane) was used for RNA gel blot analysis and hybridized with DIG-labeled expansin probes. The top section shows the Northern blot hybridization while the bottom section shows the ethidium bromide-stained rRNA bands as a loading control of the gel. DAA = days after anthesis.

fruit growth (59 DAA) and then increased rapidly, in 'Huaizhi' pericarp. In addition, the mRNA of $L c E x p 2$ could only be detected in pericarp of 'Huaizhi' but not detected in pericarp of 'Nuomici'. Previous studies have shown that the expansins were involved in fruit softening and cell wall loosening and extension relaxation through its action on hemicellulosic compounds (Brummell et al., 1999; McQueen et al., 1992; Rose et al., 1997). As the pericarp growth rate cannot follow aril rapid growth in 'Nuomici', high skin cracking in the cultivar could be accounted for the different expression patterns of two expansin genes in the pericarp and aril growth.

RNA gel blot analysis was used to examine the two expansin genes in a range of other tissues ( $\mathrm{Li}$ et al., 2003b). LcExpl and LcExp2 had a lower expression in leaves compared with that of pericarp or aril, and scarcely expressed in young roots, mature roots, mature shoots and seeds (Fig. 5). The fact that LcExp1 


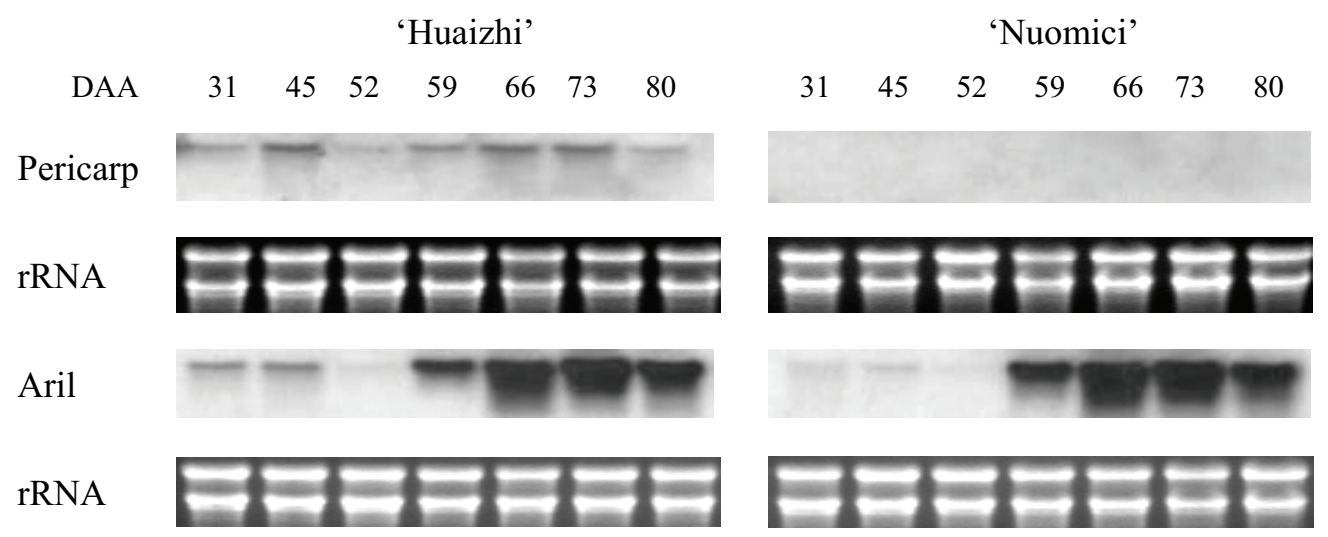

Fig. 4. Changes in mRNA accumulation of $L c E x p 2$ in pericarp and aril of 'Nuomici' and 'Huaizhi' developing litchi fruit. Total RNA (10 $\mu \mathrm{g}$ per lane) was used for RNA gel blot analysis and hybridized with DIG-labeled expansin probes. The top section shows the Northern blot hybridization while the bottom section shows the ethidium bromide-stained rRNA bands as a loading control of the gel. DAA = days after anthesis.

didn't accumulate whereas $L c E x p 2$ slightly expressed in young shoots further suggested that LcExpl and LcExp2 are involved in the regulation of growth of litchi pericarp or aril rather than in other tissues.

\section{Literature Cited}

Abuhasan, M.D. and P.K. Chattopadhyay. 1996. Correlation of pulp nitrogen, phosphorus and potassium and peel calcium with fruit cracking in litchi (Litchi chinensis Sonn). Indian J. Agr. Sci. 66:25-27.

Brummell, D.A., M.H. Harpster, and P. Dunsmuir. 1999. Differential expression of expansin gene family members during growth and ripening of tomato fruit. Plant Mol. Biol. 39:161-169.

Cosgrove, D.J. 1999a. Cell wall loosening by expansins. Plant Physiol. 118:333-339.

Cosgrove, D.J. 1999b. Enzymes and other agents that enhance cell wall extensibility. Annu. Rev. Plant Physiol. Plant Mol. Biol. 50:391-417.

Cosgrove, D.J. 2000a. Loosening of plant cell walls by expansins. Nature 407:321-326.

Cosgrove, D.J. 2000b. Expansive growth of plant cell walls. Plant Physiol. Biochem. 38:109-124.

Darley, C.P., A.M. Forrester, and S.J. McQueen-Mason. 2001. The molecular basis of plant cell extension. Plant Mol. Biol. 47:179-195.

Harrison, E.P., S.J. McQueen-Mason, and K. Manning. 2001. Expression of six expansin genes in relation to extension activity in developing strawberry fruit. J. Expt. Bot. 52:1437-1446.

Hayama, H., T. Shimada, T. Haji, A. Ito, Y. Kashimura, and H. Yoshioka. 2000. Molecular cloning of a ripening-related expansin cDNAin peach: Evidence for no relationship between expansin accumulation and change in fruit firmness during storage. J. Plant Physiol. 157:567-573.

Hiwasa, K., J. K.C. Rose, R. Nakano, A. Inaba, and Y. Kubo. 2003. Differential expression of seven $\alpha$-expansin genes during growth and ripening of pear fruit. Physiol. Plant. 117:564-572.

Huang, X.M., H.C.Wang, J.G. Li, J. Li, J. Yin, W. Yuan, J. Lu, and H.B. Huang. 2003. An overview of calcium's role in lychee fruit cracking. Acta. Hort. 665:231-240.

Huang, H.B. and J.K. Xu. 1983. The developmental patterns of fruit tissues and their correlative relationships in Litchi chinensis Sonn. Sci. Hort. 19:335-342.

Huang, X.M., H.C. Wang, F.F. Gao, and H.B. Huang. 1999. A comparative study of the pericarp of litchi varieties susceptible and resistant to fruit-cracking. J. Hort. Sci. Biotechnol. 74:351-354.

Li, J.G, H.B. Huang, and F.F. Gao. 2001. An overview of litchi fruit cracking. Acta. Hort. 558:205-208.

Li, J.G., X.M.Huang, and H.B.Huang. 2003a.Comparison of the activities of enzymes related to cell-wall metabolism in pericarp between litchi varieties: Susceptible and resistant to fruit cracking. J. Plant Physiol. Mol. Biol. 29:141-146.

\section{MR OR YS MS Leaves Seeds YP MP YA MA}

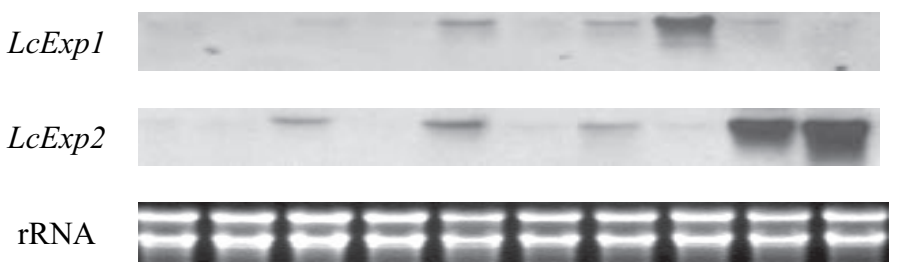

Fig. 5. Expression of $L c E x p 1$ and $L c E x p 2$ in different tissues of 'Nuomici' litchi. Total RNA (10 $\mu \mathrm{g}$ per lane) was used for RNA gel blot analysis and hybridized with DIG-labeled expansin probes. The top section shows the Northern blot hybridization while the bottom section shows the ethidium bromide-stained rRNA bands as a loading control of the gel. YR= young roots, $M R=1$-year-old mature roots, $\mathrm{YS}=$ young shoots, $\mathrm{MS}=1$-year-old mature shoots, $\mathrm{YP}=$ young pericarp at $31 \mathrm{~d}$ after anthesis (DAA), MP = mature pericarp at $80 \mathrm{DAA}, \mathrm{YA}=$ young aril at $55 \mathrm{DAA}$, and $\mathrm{MA}=$ mature aril at $80 \mathrm{DAA}$.

Li, Y., L. Jones, and S.J. McQueen-Mason. 2003b. Expansins and cell growth. Curr. Opin. Plant Biol. 6:603-610.

Li, Y., C.P. Darley, V. Ongaro, A. Fleming, O. Schipper, S.L. Baldauf, and S.J. McQueen-Mason. 2002. Plant expansins are a complex multigene family with an ancient evolutionary origin. Plant Physiol. 28:854-864

Lin, L.W. 2001. Effect of mineral nutrient on fruit cracking rate of Litchi chinesis Sonn. Soil Environ. Sci. 10:55-56.

McQueen-Mason, S.J. and D.J. Cosgrove. 1994. Disruption of hydrogen bonding between plant cell wall polymers by proteins that induce wall extension. Proc. Natl. Acad. Sci. USA. 91:6574-6578.

McQueen-Mason, S.J., D.M. Durachko, and D.J. Cosgrove. 1992. Two endogenous proteins that induce cell wall extension in plants. Plant Cell 4:1425-1433.

Peng J., X.D. Tang, and H.Y. Feng. 2004. Effects of brassinolide on the physiological properties of litchi pericarp (Litchi chinensis cv. Nuomoci). Sci. Hort. 101:407-416.

Rose, J.K.C., H.H. Lee, and A.B. Bennett. 1997. Expression of a divergent expansin gene is fruit-specific and ripening-regulated. Proc. Natl. Acad. Sci. USA. 94:5955-5960.

Sharma, S.B. and P.K. Ray. 1987. Fruit cracking in lychee-A review. Haryana J. Hort. Sci. 16:11-15.

Trivedi, P.K. and P. Nath. 2004. MaExp1, an ethylene-induced expansin from ripening banana fruit. Plant Sci. 167:1351-1358.

Wan, C.Y. and T.A. Wilkins. 1994. A modified hot borate method significantly enhances the yield of high quality RNA from cotton (Cossypium hirsutum L.). Anal. Biochem. 223:7-12.

Whitney, S.E.C., M.J. Gidley, and S.J. McQueen-Mason. 2000. Probing expansin action using cellulose/hemicellulose composite. Plant J. 22:327-334. 